\title{
Effects of Support and Heat Dissipation in Thermal Stress Cleaving of Thin Glass Plates*
}

\author{
Fumitaka MOTOMURA ${ }^{* *}$, Yasufumi IMAI ${ }^{* *}$ and Akihide SAIMOTO** \\ **Department of Mechanical Systems Engineering, Nagasaki University, \\ 1-14 Bunkyomachi, Nagasaki-shi, Nagasaki, 852-8521, Japan \\ E-mail: motomura@nagasaki-u.ac.jp
}

\begin{abstract}
Numerical analysis was conducted to solve the problems encountered in the thermal stress cleaving of borosilicate-glass plate of $50 \mu \mathrm{m}$ thick using $\mathrm{CO}_{2}$ laser with the speed over $100 \mathrm{~mm} / \mathrm{s}$. We investigated the influence of constraint and the effect of heat dissipation from the surface. It is concluded that the constraint of out-of-plane deformation does not influence the distribution of thermal stress intensity factor in the thickness and higher cleaving velocity may be attained with increase of heat dissipation.
\end{abstract}

Key words: Thermal Stress, Stress Intensity Factor, Thermal Stress Cleaving, Finite Element Method, Out-of-plane Deformation, Heat Dissipation, Thin Glass Plate

\section{Introduction}

Substrate glass plates of liquid crystal and plasma display panel are expected to become thinner as thinner displays have been desired from the ecological view point. The thickness is now, $0.7 \mathrm{~mm}$ for the liquid crystal displays and has been shifting thinner to $0.4 \mathrm{~mm}$. The latest investigation said that the thickness of display parts of organic electro-luminescence (OEL) is possibly $0.3 \mathrm{~mm}$ using substrate glasses of thickness $0.1 \mathrm{~mm}$ or less ${ }^{(1)}$. In manufacturing these displays, cutting process of substrate glasses is inevitable and a glass cutter like a "penett", which is a wheel-type tool of small diameter, is used as a common tool. This scribing method, however, has disadvantage such as generation of micro-cracks and particles. They may be caused by high contact loads. Therefore, when this method is applied to very thin glass plates, $50 \mu \mathrm{m}$ for instance, controlling contact loads will become a high-priority issue to suppress the generation of defects as little as possible. Contrasting to the above scribing method, there is a non-contact one such as the thermal stress cleaving $^{(2)-(10)}$ where no cutting chips are generated at all. This technique has the feature that a single crack is made to propagate by thermal stresses induced by laser irradiation. This has been paid attention as a processing method of brittle materials like glass plates with the progress of laser technique. The characteristic of non-contact processing is promising for very thin glass plates because high edge strength is expected without fatal defects like micro-cracks.

For the thermal stress cleaving of a borosilicate-glass plate about $1 \mathrm{~mm}$ thick, cutting speed using single heat source is bounded up to about $50 \mathrm{~mm} / \mathrm{s}$ whereas $100 \mathrm{~mm} / \mathrm{s}$ is desired for productive use. This is simply because irradiated energy is severely restricted so that the temperature should be under the melting point. The above may be the main reason why the thermal stress cleaving has not been employed as an ordinary processing method. The temperature rise of the heated area is exactly proportional to the heating energy but is almost independent to the plate thickness since $\mathrm{CO}_{2}$ laser is absorbed completely within a 
surface layer. The plate thickness, however, concerns with required heating power to cleave the plate at a certain speed. It has been revealed that almost the same power density per thickness is required for the same cleaving speed and for higher cleaving speed, higher power density is required. Then, even if heating energy is limited by the temperature rise, its density per thickness increases with reduction of plate thickness. Thin glass plates, therefore, can be cleaved at higher speed than thick plates under the same limitation of temperature rise.

Actually we have examined a thermal stress cleaving of borosilicate-glass plates of $50 \mu \mathrm{m}$ using $\mathrm{CO}_{2}$ laser and confirmed that the cleaving is possible at the speed over $100 \mathrm{~mm} / \mathrm{s}$. In the experiment, however, we observed out-of-plane deformation of the plate and instability of crack propagation. The latter may be caused by the former. In order to realize stable crack propagation, glass plates must be supported by an appropriate manner, such as using a suction stage so that out-of-plane deformation is reduced. Adding this, appropriate heating condition must be concerned to reduce the temperature rise.

In this paper, we investigated how the constraint of out-of-plane deformation influences the thermal stress intensity factor through numerical analyses of thermal stress cleaving. We also investigated the effect of heat dissipation from the surface.

\section{Analytical method}

\subsection{Analytical models in FEM}

FEM was used to simulate the thermal stress cleaving. Table 1 shows used thermal and mechanical properties of borosilicate-glass at room temperature. The temperature dependency of those properties was not considered. The material was a borosilicate-glass which was heated with an areal irradiation of $\mathrm{CO}_{2}$ laser. Geometry of analyzed model is shown in Fig.1. The uniformly heated area moves along the $x$-axis at a constant velocity. Heated diameter was fixed $5 \mathrm{~mm}$ and the heated surface is $z=0$ plane in Fig.1. The plate surface is square with side length $100 \mathrm{~mm}$. The crack propagates toward the positive $x$-axis in the symmetric plane, $y=0$. The temperature field when a heat source arrived at a certain position was used to analyze the singular stress fields. The crack front line was assumed to be straight and perpendicular to the surface and to follow the moving heat source. The absorption of $\mathrm{CO}_{2}$ laser to a borosilicate-glass is quite high. Therefore, the heat supply due to a laser irradiation was assumed to occur on a surface of the heating side.

Example of mesh division in the $x-y$ plane is shown in Fig.2 for 3-dimensional analysis of $50 \mu \mathrm{m}$ thick plate. The plate thickness was divided equally into four for three kinds of plate thickness $50 \mu \mathrm{m}, 0.4 \mathrm{~mm}$ and $1.0 \mathrm{~mm}$. Numbers of total nodes were 16,637 and elements were 3,312 .

Quadratic twenty-node elements were used in three-dimensional case. To estimate stress intensity factors along the crack front line, virtual crack closure integral method was used. $K_{\mathrm{I}}$ were estimated at mid-side nodes of crack front elements. As a plate becomes thinner, the temperature and stress variation in the thickness become smaller until two-dimensional analysis may approximate the situation. Therefore, 2-dimensional analyses were also examined using $1 \mathrm{~mm} \times 1 \mathrm{~mm}$ quadratic eight-node elements.

Table 1 Thermal and mechanical properties of borosilicate-glass at room temperature

\begin{tabular}{|l|l|}
\hline Coefficient of Linear Thermal Expansion $\alpha\left[10^{-6} / \mathrm{K}\right]$ & 4.5 \\
\hline Thermal Conductivity $\lambda[\mathrm{W} /(\mathrm{m} \mathrm{K})]$ & 1.1 \\
\hline Thermal Diffusivity $\kappa\left[10^{-6} \mathrm{~m}^{2} / \mathrm{s}\right]$ & 0.554 \\
\hline Young's Modulus $E[\mathrm{GPa}]$ & 64.7 \\
\hline Poisson's Ratio $v[-]$ & 0.235 \\
\hline
\end{tabular}




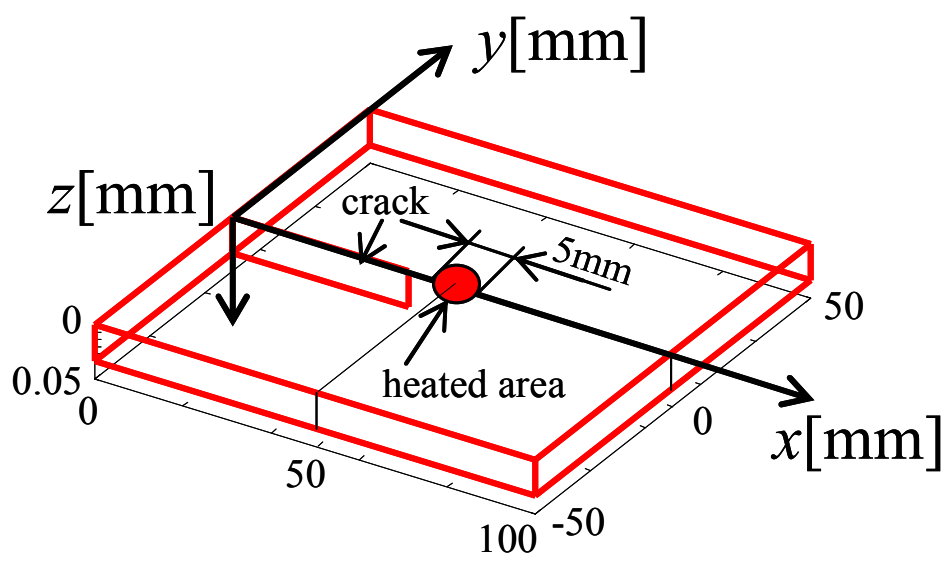

Fig. 1 Analytical model

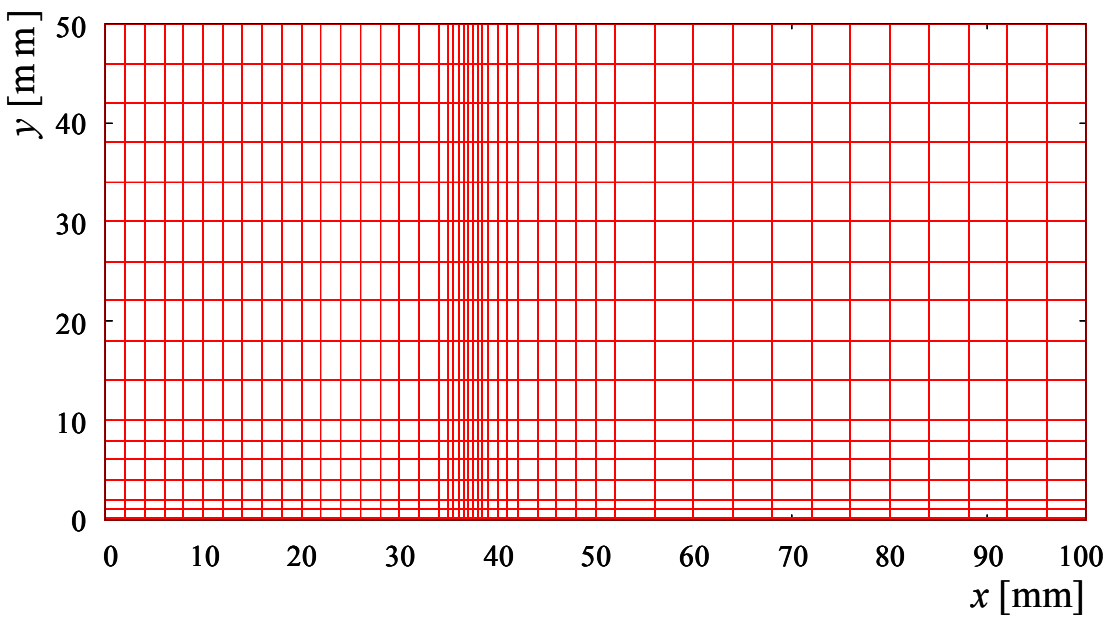

Fig. 2 Mesh division

\subsection{Heat convection from plate surfaces}

In a two-dimensional analysis of temperature field, heat flux due to heat convection at a plate surface was considered as follows. The energy balance on an element of volume $d x \times d y \times b$ is expressed as,

$$
\begin{aligned}
& c \rho d T b d x d y=-\lambda \frac{\partial T}{\partial x} b d y d t+\lambda \frac{\partial}{\partial x}\left(T+\frac{\partial T}{\partial x} d x\right) b d y d t-\lambda \frac{\partial T}{\partial y} b d x d t \\
& +\lambda \frac{\partial}{\partial y}\left(T+\frac{\partial T}{\partial y} d y\right) b d x d t-h\left(T-T_{\infty}\right) d x d y d t+Q^{\prime} b d x d y d t
\end{aligned}
$$

Where, $c, \rho, \lambda$ are specific heat, density and thermal conductivity, respectively. $b$ is a plate thickness, $Q$ ' is a volumetric heat and $h$ is a heat transfer coefficient at a plate surface to a surrounding $T_{\infty}$.

Differential equation of the heat convection is obtained as,

$$
\lambda\left(\frac{\partial^{2} T}{\partial x^{2}}+\frac{\partial^{2} T}{\partial y^{2}}\right)+Q^{\prime}-\frac{h}{b}\left(T-T_{\infty}\right)=c \rho \frac{\partial T}{\partial t}
$$

In Eq.(2), the third term on the left-hand side corresponds to the heat dissipation. This term is proportional to the temperature rise $T-T_{\infty}$ and can be treated as a negative heat added to volumetric heat $Q^{\prime}$. In the equation, heat convection was counted at only single surface. When both surfaces of the plate are considered, the heat dissipation term becomes double. 


\section{Analytical results}

\subsection{Temperature field and stress intensity factor}

Figure 3 shows the temperature distributions on a heating line for three kinds of plate thickness, $1.0 \mathrm{~mm}, 0.4 \mathrm{~mm}$ and $50 \mu \mathrm{m}$ at the time when a center of heated area has arrived at $x=50 \mathrm{~mm}$. Velocity of a moving heat was $100 \mathrm{~mm} / \mathrm{s}$. Heat transfer coefficient was $200 \mathrm{~W} / \mathrm{m}^{2} \mathrm{~K}$ and heat transfer at both surfaces were adopted. Figure 3(a) shows temperature distributions at the heated surface and Fig.3(b) at the back surface. Heating energy $Q$ 's were different with plate thickness, being proportional to the thickness. Heating density per plate thickness was fixed $20 \mathrm{~W} / \mathrm{mm}$ so that almost the same level of stress field was obtained irrespective to thickness. Time increment $1 \mathrm{~ms}$ was used to calculate the transient temperature fields. The maximum temperature rise at the heated surface of $50 \mu \mathrm{m}$ plate was about $20 \mathrm{~K}$ contrasting to the temperature rise about $160 \mathrm{~K}$ for $1 \mathrm{~mm}$ plate. The difference is just because of different heating energy. The maximum temperature is attained at a point on the backward boundary of heated area. Temperature rise in the back surface of $1 \mathrm{~mm}$ plate is quite small especially near the heating position. Apparently large temperature gradient in the thickness appears. The intensity of gradient is larger when the plate is thicker. Temperature distributions on the heated surface and the back surface are hardly different for the $50 \mu \mathrm{m}$ plate.

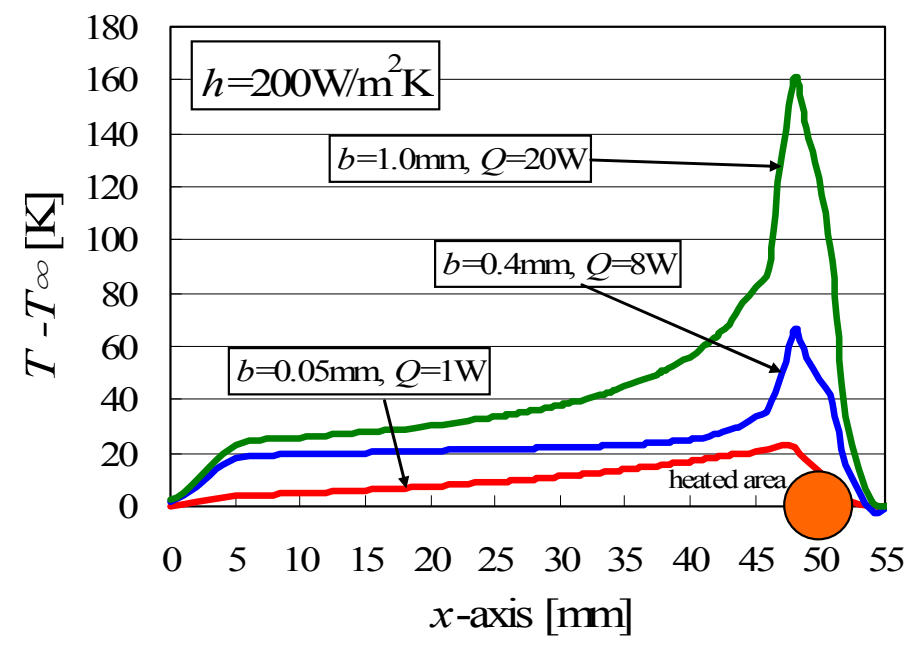

(a) Heated surface

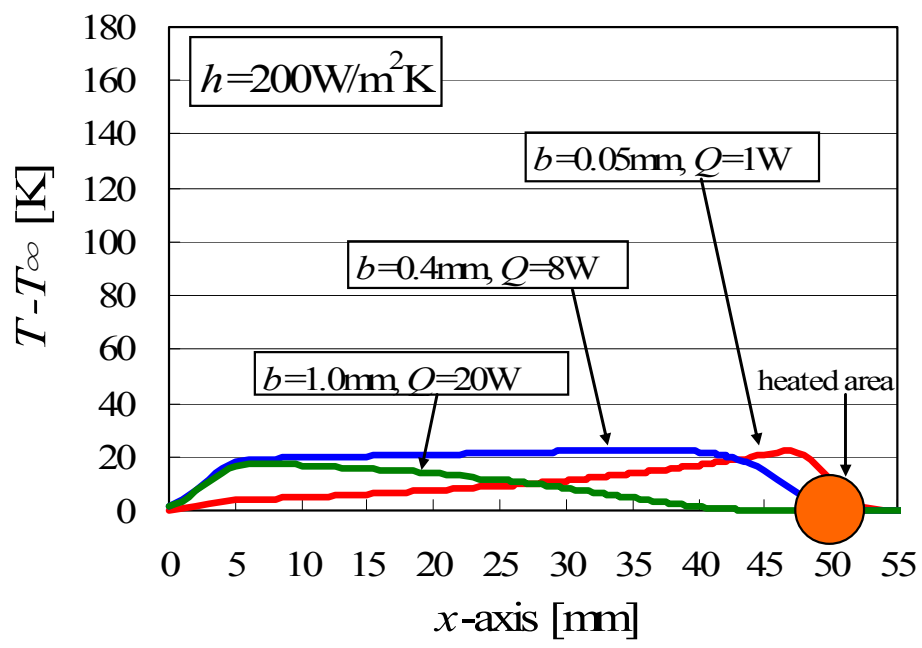

(b) Back surface

Fig. 3 Temperature distribution on the $x$-axis 
Figure 4 shows the variation of stress intensity factor using above temperature fields, obtained at the middle of plate thickness as a function of crack front location, $c f l$, which is $x$-coordinate of crack front. That is, at the time when a center of heated area arrived at $x=50 \mathrm{~mm}$ with the heat dissipation, $h=200 \mathrm{~W} / \mathrm{m}^{2} \mathrm{~K}$. Results for three kinds of plate thickness, $50 \mu \mathrm{m}, 0.4 \mathrm{~mm}$ and $1 \mathrm{~mm}$ are shown. In this figure, only $q=20 \mathrm{~W} / \mathrm{mm}$ case was shown. But actual $K_{\mathrm{I}}$ value can be estimated for any heating power $Q$ since $K_{\mathrm{I}}$ value is exactly proportional to the heating density $q$. It should be also noted that $K_{\mathrm{I}}$ variation was almost the same in spite of different temperature distributions as seen in Fig.3. This is the reason why different heating energy was used for different plate thickness so that the heating density per thickness was identical. When a crack front locates near a heated area, $K_{\mathrm{I}}$ becomes negative. $K_{\mathrm{I}}$ value changes positive as a crack front recedes from a heated area. $K_{\mathrm{I}}$ varies showing a peak for a very thin plate as seen for $50 \mu \mathrm{m}$ plate though the variation depends on the heating conditions and the geometry. If $K_{\mathrm{I}}$ value at a certain crack front location exceeds the fracture toughness, that crack location may be realized.

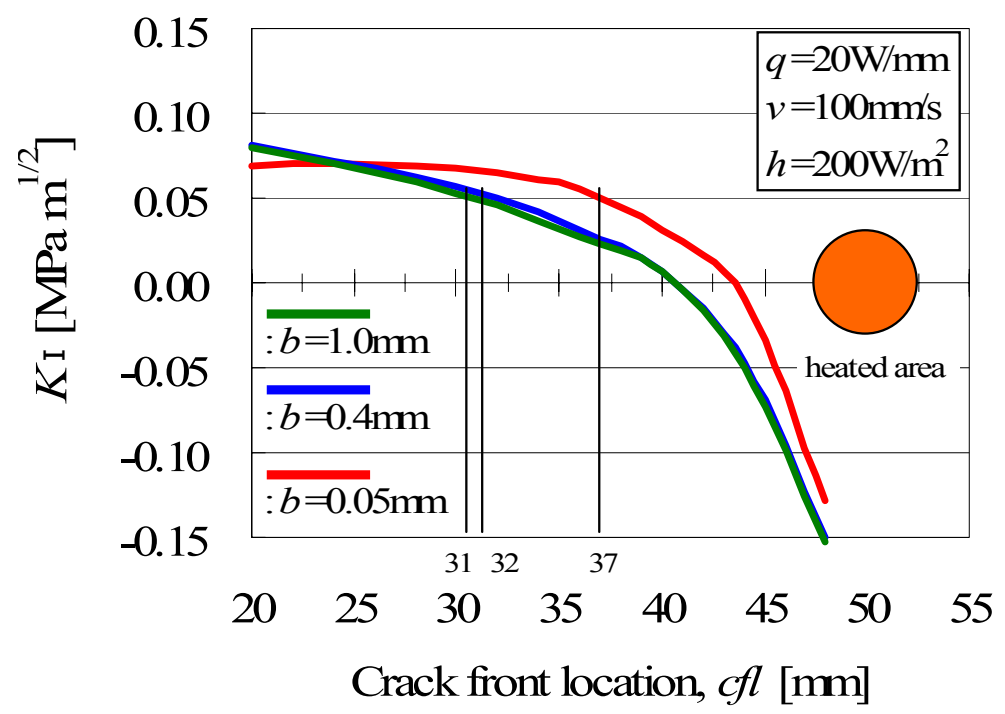

Fig. $4 K_{\mathrm{I}}$ variation as a function of the crack front location

Figure 5 shows the distribution of stress intensity factor in a plate thickness when the center of heated area locates $x=50 \mathrm{~mm}$. Different crack front locations are selected for three kinds of plate thickness so that $K_{\mathrm{I}}$ at the center of plate thickness becomes $0.05 \mathrm{MPam}^{1 / 2}$. That is, the crack front location is estimated from Fig. 4 as $c f l=37 \mathrm{~mm}$ for a $50 \mu \mathrm{m}$ thick plate, $32 \mathrm{~mm}$ for a $0.4 \mathrm{~mm}$ thick plate and $31 \mathrm{~mm}$ for a $1.0 \mathrm{~mm}$ thick plate. The distribution is almost flat for $50 \mu \mathrm{m}$ plate. In this analysis, the crack front line was assumed straight and perpendicular to the surface. The $K_{\mathrm{I}}$ at the heated surface becomes higher as a plate becomes thicker. As mentioned above, $K_{\mathrm{I}}$ decreases as crack front approaches to the center of heated area. In thick plates, therefore, the crack front near the heated surface approaches nearer to the heating center than near the back surface so that the stress intensity factor along the crack front remains the same level. Hence, the shape of crack front in the plate thickness is expected to incline in $y=0$ plane so that the crack front at the heated side precedes. Solid circles plotted on the ordinate in Fig. 5 show $K_{\mathrm{I}}$ values obtained from two-dimensional analysis in which different crack lengths were used corresponding to the three-dimensional analysis. $K_{\mathrm{I}}$ at the middle of thickness for three-dimensional analysis are well approximated by two-dimensional results. Because the distribution of $K_{\mathrm{I}}$ in the thickness is flat when a plate becomes thin, two-dimensional analysis becomes effective for thin plates. 


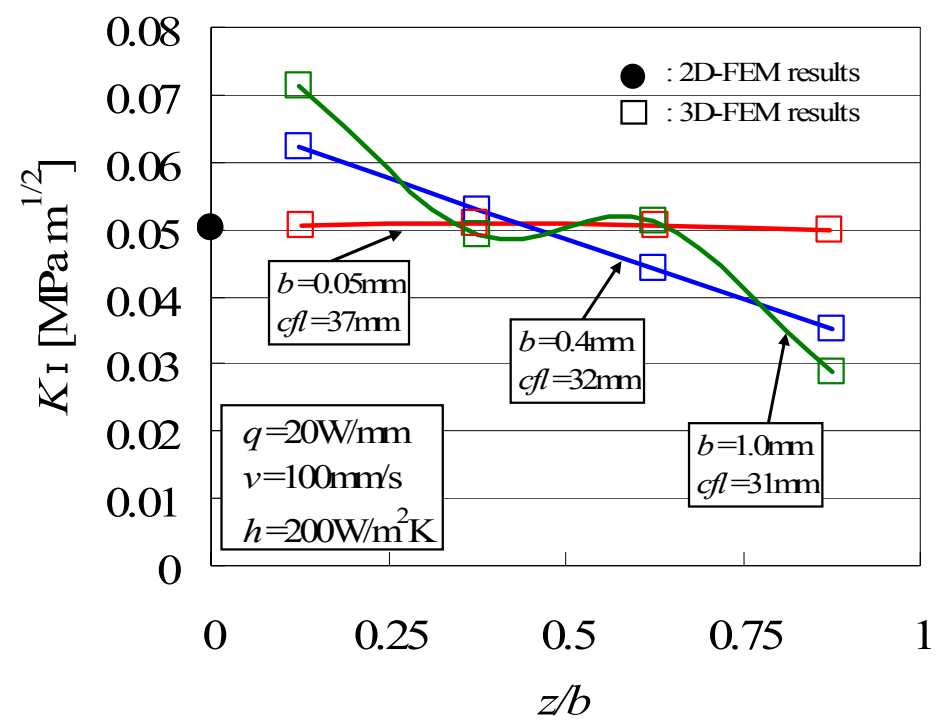

Fig. $5 K_{\mathrm{I}}$ distribution in the thickness

\subsection{Thermo-elastic deformation}

Figure 6 shows a out-of plane displacement of the heated surface of $50 \mu \mathrm{m}$ thick plate. This was obtained under the condition that the plate is free from external force, the crack front locates at $x=37 \mathrm{~mm}$ and the center of heated area arrives at $x=50 \mathrm{~mm}$. Heating power was $15 \mathrm{~W}$, which is enough to the actual thermal stress cleaving of a borosilicate-glass plate. The heated area is lifted about $20 \mu \mathrm{m}$ and at the edge about $10 \mu \mathrm{m}$ in the opposite direction. The maximum deflection becomes $30 \mu \mathrm{m}$ or more being about $60 \%$ of plate thickness. For other thicknesses, similar deflections, between $50 \%$ and $70 \%$ of the thickness, were estimated when the heating powers $120 \mathrm{~W}$ and $300 \mathrm{~W}$ were applied to $0.4 \mathrm{~mm}$ and $1.0 \mathrm{~mm}$ thick plates, respectively. These high heating energies are necessary in order to obtain the same level of $K_{\mathrm{I}}$ as the one estimated in $50 \mu \mathrm{m}$ plate. They cause, however, the temperature at the heated surface far exceeds the melting point, about $600 \mathrm{~K}$ for borosilicate-glass. Therefore, the thermal stress cleaving of relatively thick plates under such high cleaving speed as $100 \mathrm{~mm} / \mathrm{s}$ has not been realized and such large deflections have not been observed.

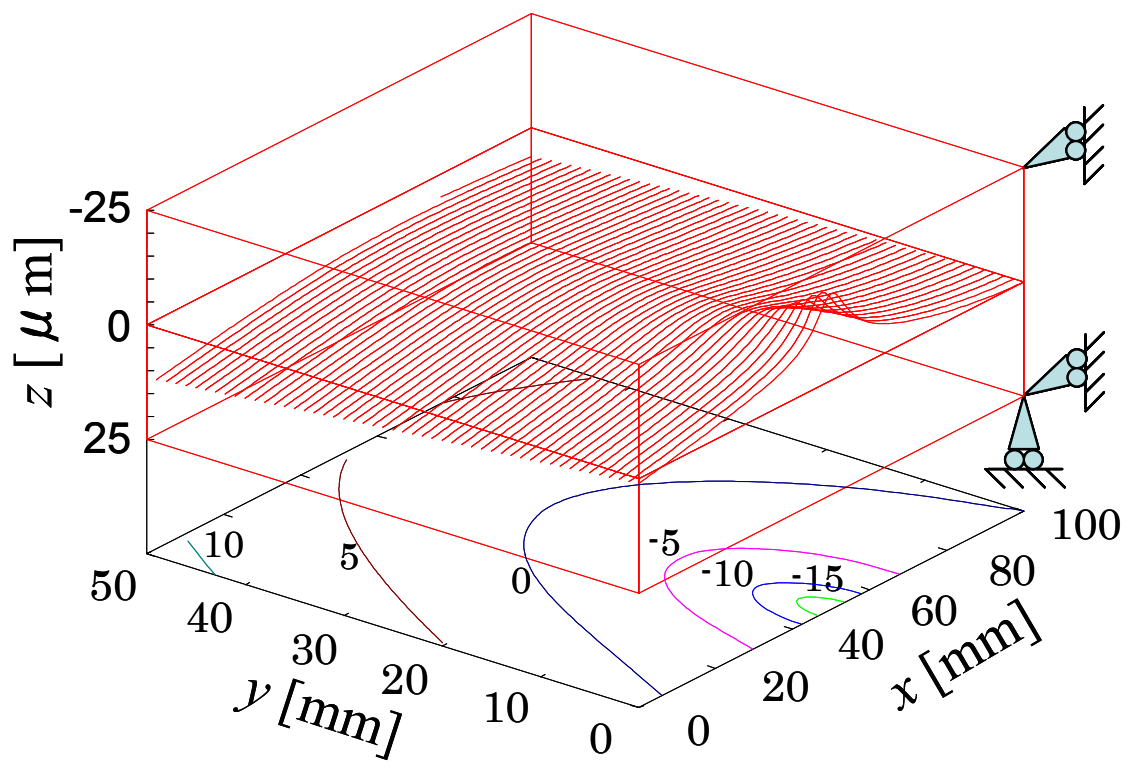

Fig.6 Out-of-plane displacement of a heated surface for the case free from external force 
If a suction stage is used to reduce the out-of plane displacement in thermal stress cleaving, it will be necessary to understand the influence of the suction force to the stress intensity factor. The frictional force might be generated between a glass plate and the stage surface in the actual situation. However, only the constraint of displacement in the $z$-direction was paid attention here. For a $50 \mu \mathrm{m}$ plate, two kinds of constraint condition were examined and stress intensity factors and thermo-elastic deformation were compared: (a) $z$-directional displacements on the line $y=0$ in the back surface are fixed (line constraint); (b) $z$-directional displacements at all nodes in the back surface are fixed (plane constraint). The plane constraint may correspond to the situation using a suction stage.

Figure 7(a) shows the out-of-plane displacement of the heated surface for the line constraint and Fig.7(b) for the plane constraint. In the case of line constraint, maximum deflection appears at the edge, about $15 \mu \mathrm{m}$ although the displacement near the heated area is suppressed. In the case of plane constraint, remarkable deflection was not caused except small deformation due to the thermal expansion in the high temperature area.

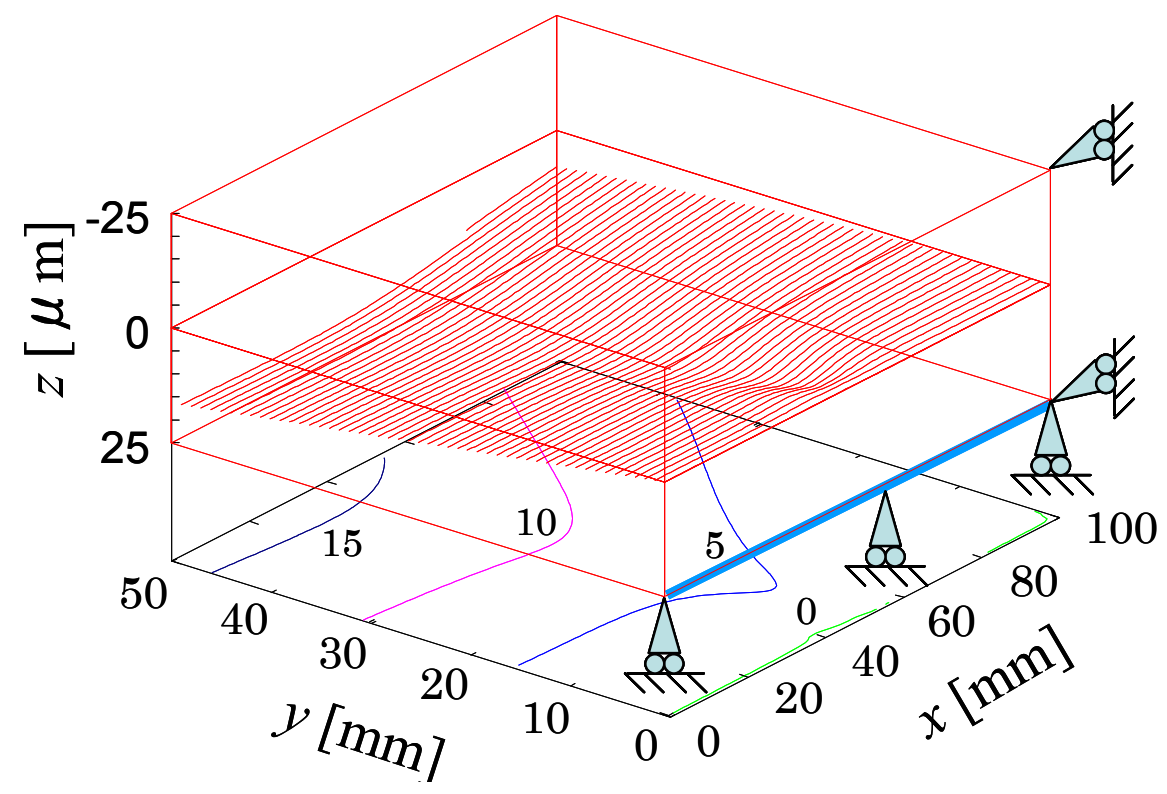

(a) Line constraint

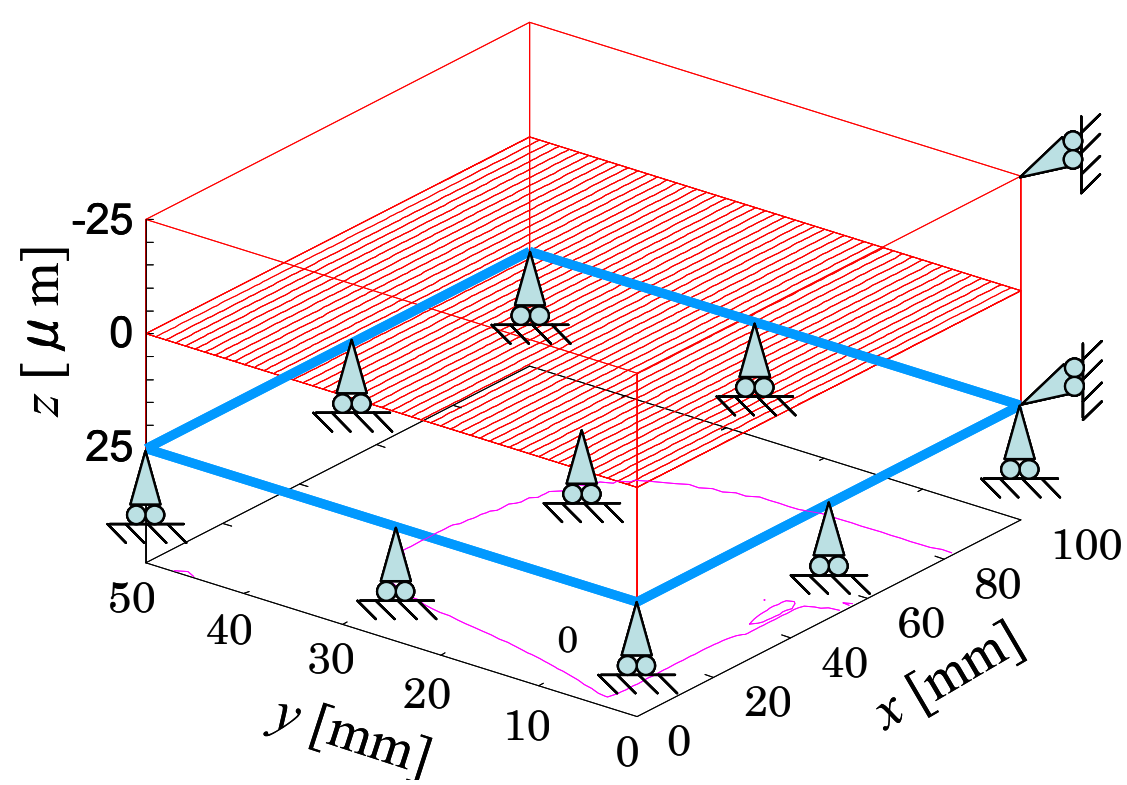

(b) Plane constraint

Fig.7 Out-of-plane displacement of the heated surface of constrained plate 
Figure 8 shows the influence of constraint to the distributions of stress intensity factor in the plate thickness. The character "free" in the figure represents the case where a plate is free from external forces. The distributions of $K_{\mathrm{I}}$ in the plate thickness seem somewhat different for different constraint conditions. But the difference is about $2 \%$. For the plane constraint, $K_{\mathrm{I}}$ is smaller near the heated surface compared to the free case and higher near the back surface. This is thought to be caused by an action of moment around the $x$-axis induced by the constraint force. The difference with constraint type, however, is quite small. The stress intensity factor of a thin plate is not influenced very much by the $z$-directional constraint and its distribution is almost flat in the thickness. Consequently, it can be said that the thermal stress cleaving of thin glass plates constrained by a suction stage can be achieved with the same heating power and cleaving speed as a free plate.

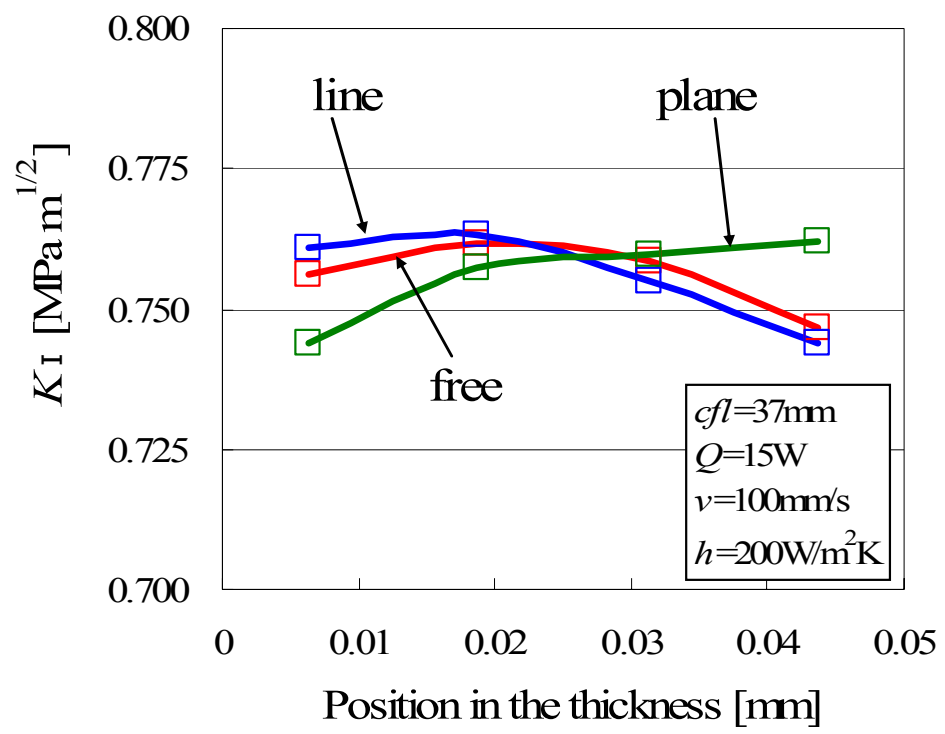

Fig.8 $K_{\mathrm{I}}$ distributions in a plate thickness for different constraint conditions

\subsection{Effect of heat dissipation from the surface}

For thin plates like $50 \mu \mathrm{m}$ thick, thermal stress fields can be approximated by the two-dimensional case because of the following reasons: (1) the temperature distribution in a plate thickness is almost flat even if the heating energy is absorbed in the surface layer; (2) even for a crack front being straight and perpendicular to the surface, distribution of stress intensity factor in the plate thickness is almost flat; (3) distribution of stress intensity factor for a "plane constraint" plate is within $2 \%$ variation in the thickness. Therefore, we will proceed with a further discussion by using results of two-dimensional analysis. It should be noted that the same discussion can be developed by using the thickness-averaged values of three-dimensional results.

Figure 9 shows how $K_{\mathrm{I}}$ changes by the presence of heat dissipation for an arbitrary crack tip location in three kinds of plate thickness, $50 \mu \mathrm{m}, 0.4 \mathrm{~mm}$ and $1.0 \mathrm{~mm}$. Temperature fields when the center of heated area arrived at $x=50 \mathrm{~mm}$ were used in all calculations. Velocity of moving heat was $100 \mathrm{~mm} / \mathrm{s}$ and heating density per thickness was $20 \mathrm{~W} / \mathrm{mm}$. The case without heat dissipation from the surface is shown in Fig.9(a). Curves of $K_{\mathrm{I}}$ for three kinds of plate thickness are presented completely in single one because the same heating density was used. Influence of heat dissipation is seen in Fig.9(b). A plate thickness becomes thinner, a distance becomes shorter between the center of heated area and a crack tip location at which $K_{\mathrm{I}}$ is zero. Note that the crack tip location giving zero $K_{\mathrm{I}}$ has important meaning: A crack can not propagate beyond this point because $K_{\mathrm{I}}$ is estimated negative 
there. $K_{\mathrm{I}}$ level is proportional to the heating energy whereas this location is independent of the heating energy. Therefore, this location can be understood to be the location of the most advanced crack tip which is attained under infinite heating energy. We will concern this crack tip location and express it as the critical crack tip location hereafter.

Figure 10 shows the variation of $K_{\mathrm{I}}$ of $50 \mu \mathrm{m}$ plate due to the effect of heat dissipation for different velocities of moving heat, (a) $100 \mathrm{~mm} / \mathrm{s}$ and (b) $50 \mathrm{~mm} / \mathrm{s}$. A critical crack tip location comes nearer to the center of heated area when heat dissipation increases. This tendency is more for lower velocity. As heat dissipation increases, $K_{\mathrm{I}}$ comes to show a peak and the peak value becomes smaller. This may be taken as shortcomings but it is not the case. If $K_{\mathrm{I}}$ is compared at the same propagating crack tip location, increase of heat dissipation increases $K_{\mathrm{I}}$ and, hence, possibly makes the propagating velocity faster.

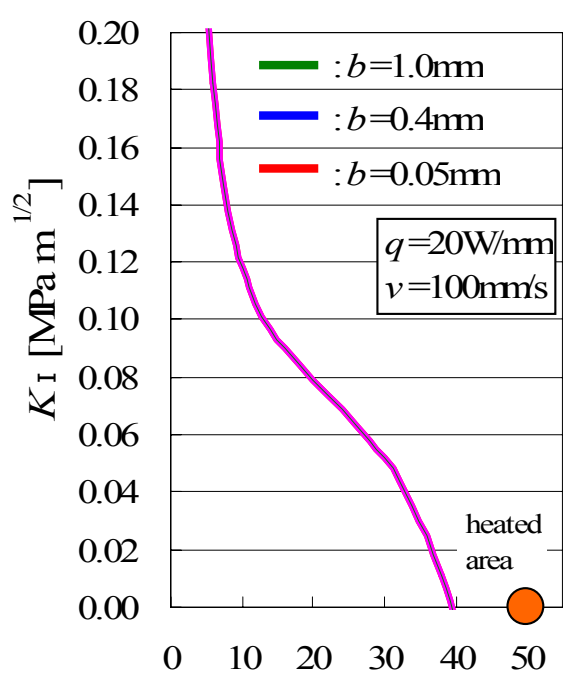

Crack tip location [mm]

(a) No heat dissipation

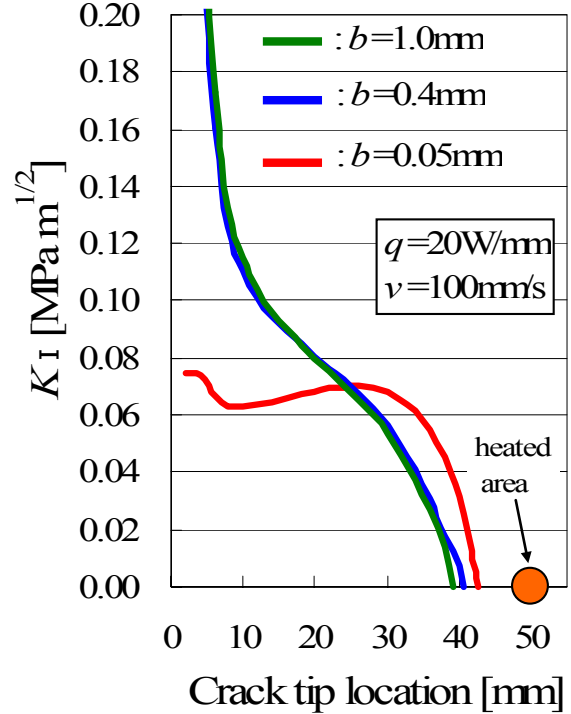

(b) Heat dissipation $\left(h=200 \mathrm{~W} / \mathrm{m}^{2} \mathrm{~K}\right)$

Fig.9 Influence of heat dissipation to the $K_{\mathrm{I}}$ variation
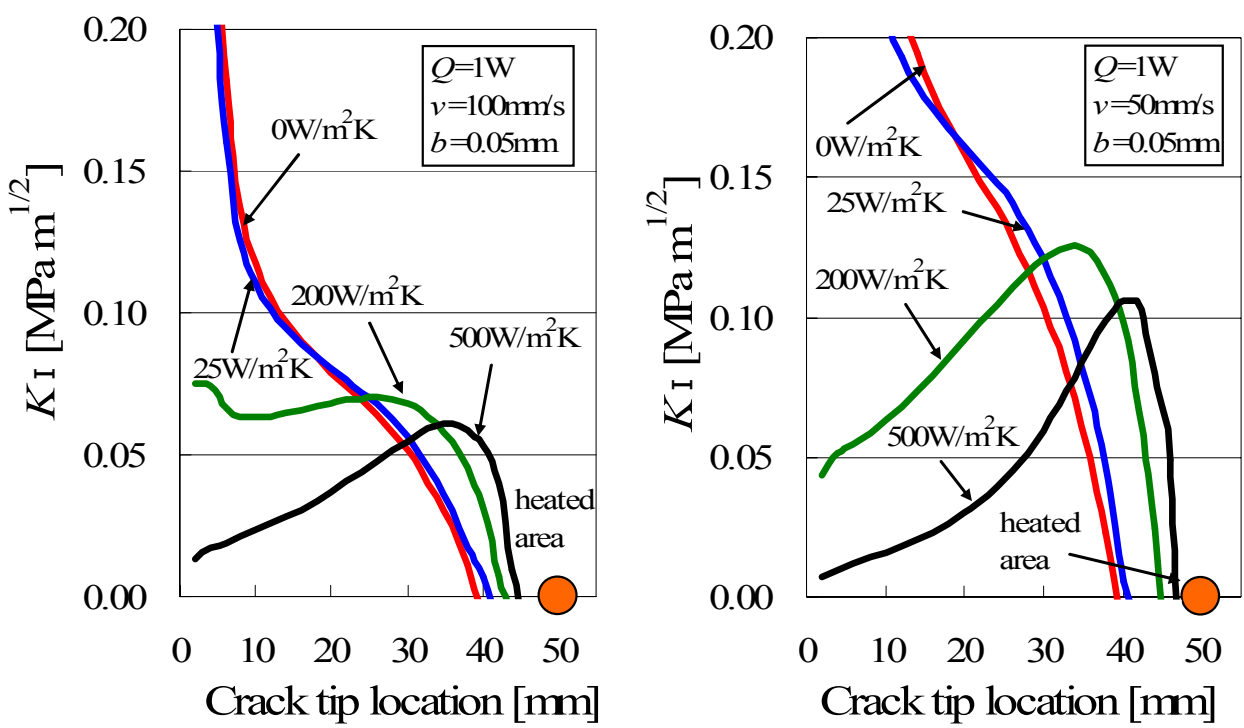

(a) Velocity of moving heat $(v=100 \mathrm{~mm} / \mathrm{s})$

(b) Velocity of moving heat $(v=50 \mathrm{~mm} / \mathrm{s})$

Fig. 10 Influence of the velocity of moving heat to the $K_{\mathrm{I}}$ variation 
Figure 11 shows how the critical crack tip location changes with heat dissipation for three kinds of velocity, $10 \mathrm{~mm} / \mathrm{s}, 50 \mathrm{~mm} / \mathrm{s}$ and $100 \mathrm{~mm} / \mathrm{s}$. The critical crack tip location deviates from a heated area with the increase of velocity. But, with the increment of heat dissipation, then, the location comes nearer to heated area for the same velocity. Consider, for example, the cleaving under $10 \mathrm{~mm} / \mathrm{s}$ and $h=20 \mathrm{~W} / \mathrm{m}^{2} \mathrm{~K}$ using appropriate heating power. The crack is expected propagating about $7 \mathrm{~mm}$ behind the center of heated area. Under enough heating energy, the same crack tip location may be attained with the velocity $100 \mathrm{~mm} / \mathrm{s}$ only by increasing the heat dissipation to $h=200 \mathrm{~W} / \mathrm{m}^{2} \mathrm{~K}$.

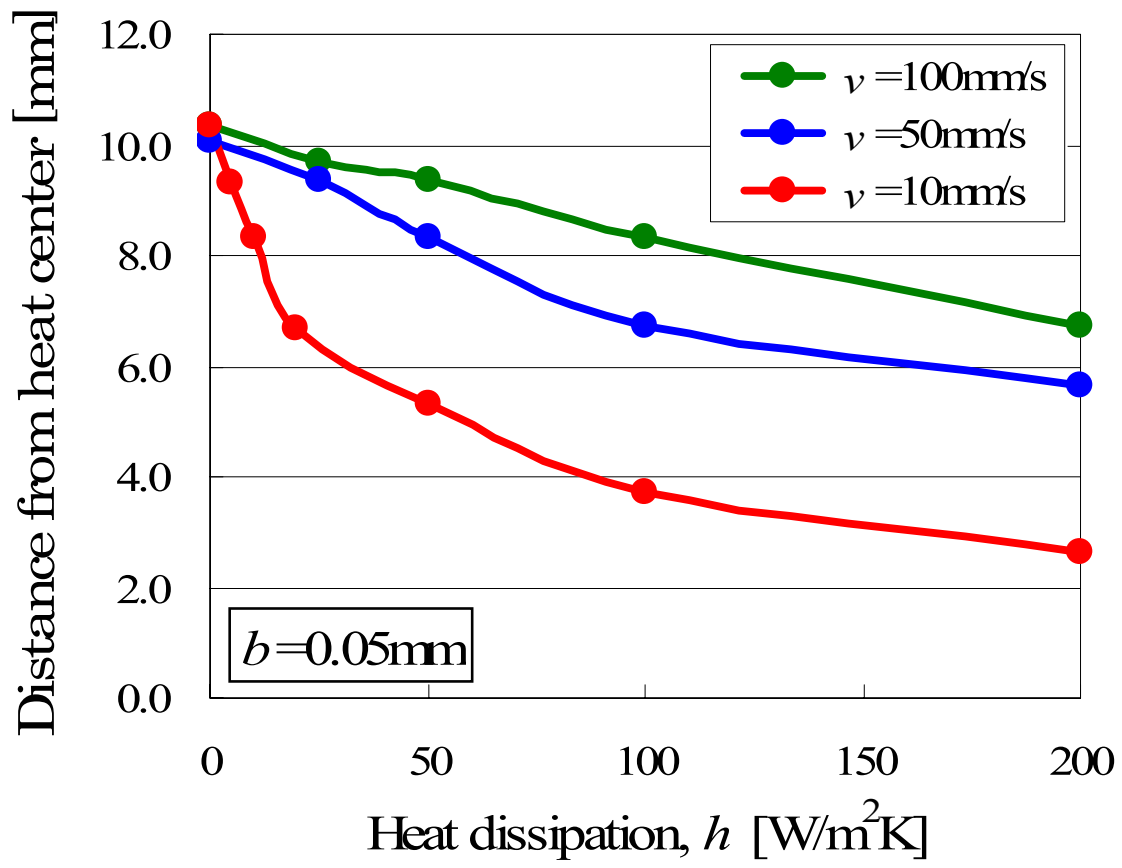

Fig.11 Influence of heat dissipation to the critical crack tip location

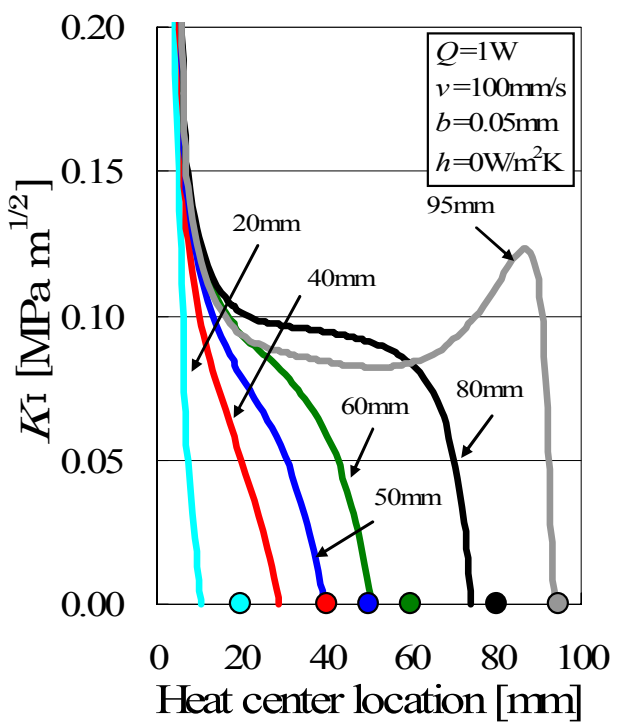

(a) Heat dissipation $\left(h=0 \mathrm{~W} / \mathrm{m}^{2} \mathrm{~K}\right)$

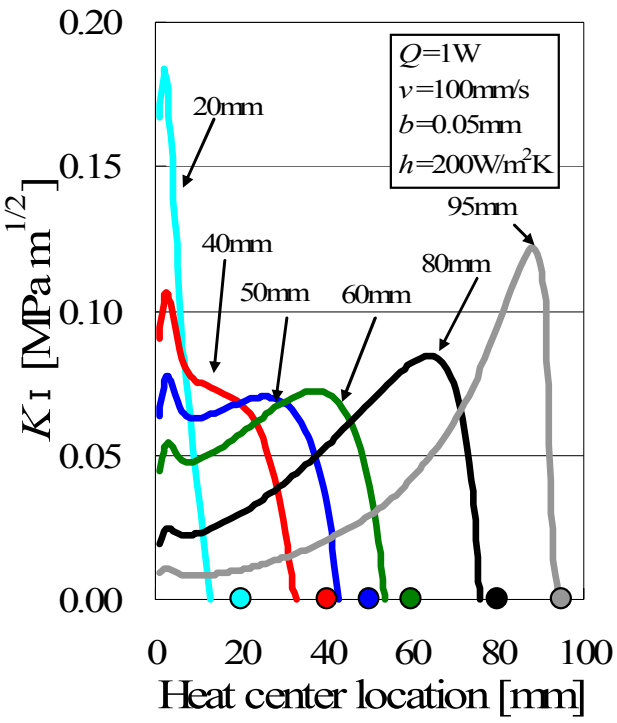

(b) Heat dissipation $\left(h=200 \mathrm{~W} / \mathrm{m}^{2} \mathrm{~K}\right)$

Fig. $12 K_{\mathrm{I}}$ variations with different locations of heated area 
The above results are obtained for the time when a center of heated area arrived at $x=50 \mathrm{~mm}$, that is, at the middle of the plate length. Results for various heating time, that is, the center of heated area advances correspondingly, are shown in Fig.12, (a) for the case without heat dissipation and (b) for heat transfer coefficient $h=200 \mathrm{~W} / \mathrm{m}^{2} \mathrm{~K}$. Except beginning and ending regions, all critical crack tip locations come nearer to corresponding centers of heated area when heat dissipation presents. At the beginning and ending regions, the inclination of $K_{\mathrm{I}}$ variation is steeper compared with ones in the middle region. This means that the location of propagating crack tip in these regions is hardly influenced by the heating energy. In Fig.13, the distance between the location of propagating crack tip and center of heated area is plotted against heating location in the case the heating power $15 \mathrm{~W}$, moving speed $100 \mathrm{~mm} / \mathrm{s}$ and $K_{\mathrm{I}}=0.75 \mathrm{MPam}^{1 / 2}$. It is expected that with the increase of heat dissipation, the propagating crack tip comes nearer to the heated area over a long middle region of the plate.

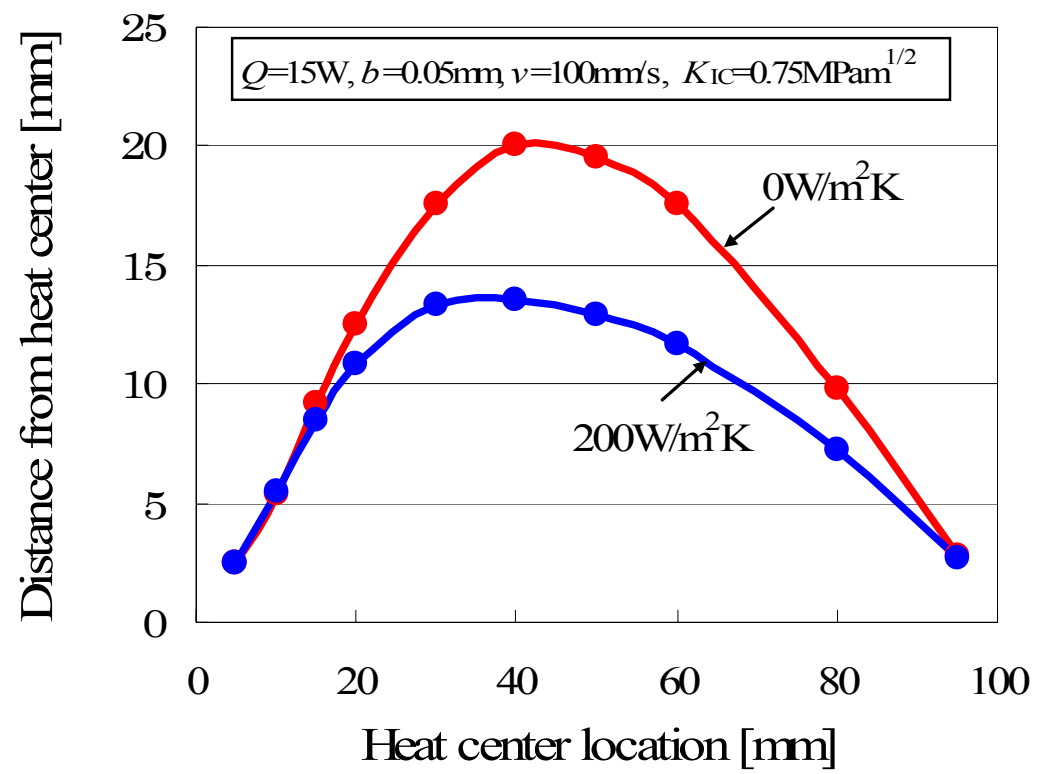

Fig.13 Estimated location of propagating crack tip in a thermal stress cleaving

\section{Conclusions}

Thermal stress fields were analyzed by finite element method in a borosilicate-glass plate heated by $\mathrm{CO}_{2}$ laser irradiation and the followings are concluded.

1. If the heating density per plate thickness is fixed, almost the same level of stress field is obtained irrespective to thickness.

2. The constraint of out-of-plane deformation does not influence much the distribution of stress intensity factor in the plate thickness. Therefore, the thermal stress cleaving of thin glass plates constrained by a suction stage can be achieved with the same heating power and cleaving speed as a free plate.

3. The distribution of $K_{\mathrm{I}}$ in the thickness becomes flat when a plate becomes thin and two-dimensional analysis becomes effective for thin plates.

4. There exists a special crack tip location where $K_{\mathrm{I}}$ becomes zero irrespective to heating energy, which can be understood to be of the most advanced crack tip under infinite heating energy. This location comes nearer to the center of heated area when heat dissipation increases.

5. Under enough heating energy, higher cleaving velocity may be attained only by increasing the heat dissipation. 


\section{References}

1) Home Page of CEATEC JAPAN, URL; http://www.ceatec.com.

2) Yasufumi IMAI, Hideki MORITA, Tooru TAKASE, and Hiroyuki KOGA, Possibility of Employing Thermal Stresses as a Cutting Device for Brittle Materials, Journal of Japan Society of Mechanical Engineers, A55-509, 147 (1989).

3) Hideki MORITA, and Yasufumi IMAI, Crack Extension Induced by Thermal Stresses Associated with Uniform Heating in a Circle, Journal of Japan Society of Mechanical Engineers, A56-524, 850 (1990).

4) Yasufumi IMAI, Hideki MORITA and Tooru TAKASE, Stress Intensity Factor for a Semi-infinite Crack Heated by a Moving Source of Heat, Journal of Japan Society of Mechanical Engineers, A56-524,855 (1990).

5) Yasufumi IMAI, Katsuhisa HIRATA and Toru TAKASE, Crack Tip Opening due to Crack-face Heating in an Infinite Plate, Journal of Japan Society of Mechanical Engineers, A57-544, 2897 (1991).

6) Toru TAKASE, Ryuji KUROKAWA and Yasufumi IMAI, Thermal Stress Cutting of Cylindrical Brittle Materials, Journal of Japan Society of Mechanical Engineers, A60-570, 385 (1994).

7) Akihide SAIMOTO, Yasufumi IMAI and Hideki MORITA, Thermal Stress Intensity Factor of Semi-Infinite Crack due to Crack Face Heating, Journal of Japan Society of Mechanical Engineers, A62-597, 1172 (1996).

8) Hiroshi SAWADA, Yasufumi IMAI, Akihide SAIMOTO and Fumitaka MOTOMURA, Restraint of the Temperature Rise in Thermal Stress Cleaving of a Thin Strip Using Nd:YAG Laser, Journal of the Japan Society for Precision Engineering, 64-11, 1638 (1998).

9) Akihide SAIMOTO, Hiroshi SAWADA, Yasufumi IMAI, Thermal Stress Cleaving of Brittle Thin Strip Using Line Heat Source and the Size Effect, J. Soc. Mat. Sci., Japan, 47-8, 813 (1998)

10) Yasufumi IMAI, Akihide SAIMOTO and Fumitaka MOTOMURA, Thermal Stress Cleaving near a Free Edge Using a Moving Heat Source, Journal of Japan Society of Mechanical Engineers, A68-670, 993 (2002). 